\title{
To Report or not: The Dilemma of Reporting Medical Errors among Physicians
}

Saleh M. Aldaqal ${ }^{1 *}$, Munaser S. Al-Amoodi ${ }^{1}$

1.Department of Surgery, Faculty of Medicine, King Abdulaziz University, Jeddah, Saudi Arabia

\begin{abstract}
Objectives: Medical errors (ME) can be an important cause in hindering the improvement in the quality of service provided to patients as well as their wellbeing. Underreporting ME by health professionals might prevent identifying the areas that require attention. This in turn, will not only affect the quality of service provided to patients, but also it might increase the rate of litigation and patient harm. Methods and Materials: In a questionnaire on reporting medical errors (RME), we evaluated demographics of physicians, their knowledge on RME and attitude towards reporting and practice of reporting and/or concealing their errors. Results: Reporting was significantly higher among consultants, $(P=0.001)$. Furthermore, 48\% $(n=81)$ confessed committing ME, of which $35 \%(n=59)$ had reported it. The majority of participants $81 \%(n=137)$ consider reporting ME an ethical issue. Conclusion: There is an agreement amongst physicians that reporting $\mathrm{ME}$ is an ethical issue. Reinforcement of RME and reducing ME can be achieved by implementing strict guidelines, training personnel efficiently and using the experience of professionals in their appropriate fields.
\end{abstract}

Keywords: Medical errors; Reporting medical error; Physician attitude

\section{Introduction}

In the medical field, just as in any practice, the occurrence of errors, mistakes and inaccuracies is inevitable. However many authorities have been attempting to investigate methods of reducing and possibly eliminating human errors and their potential hazardous squeals $(1,2)$. Over the years, manual work has been replaced by computerized digital systems in the hope of reducing human work-related errors which is extremely crucial particularly in hospitals. When it comes to a patient's life and well-being, mistakes may be unforgivable (3). Medical error can result in tremendous damage and unwanted consequences; not only the patient's health can be in turmoil but also the treating physician can be greatly affected $(4,5)$. When any member of the health care system

\section{Corresponding author:}

Saleh Aldaqal

Department of Surgery, Faculty of medicine, King Abdulaziz University P.O. Box 80215, Jeddah 21589 Saudi Arabia Tel: 012-6408346, Fax: 012-6408347,E-mail: sdaqal@yahoo.com,munas88@yahoo.com

Received: 23-12-2013, Accepted: 02-01-2014, Published:

04-01-2014 DOI: 10.7575/aiac.abcmed.14.02.02.08 
makes a mistake, it may well jeopardize his/her mental status, emotions, and performance. Thus, it is imperative to find appropriate ways to help solve this problem (6). In our belief, one of the major aspects of reducing errors is to report these errors to the authorities in charge in the respective institutes. Actions, in terms of education, training, advice, system modifications, and possibly penalties, should be implemented following reporting. Physicians should also have a positive attitude towards this, and not shy away from their responsibility of reporting. Every member in a hospital should be encouraged to report and hence eliminate all possible errors so that patients can receive the best possible care from all providers.

Our study aimed to investigate the attitude of physicians in our hospital towards reporting their $\mathrm{ME}$, and to evaluate their knowledge on reporting. Furthermore, we aimed at finding the aspects behind their practice of reporting and/or concealing their errors. We also focused on investigating the possible appropriate actions to be taken following reporting of errors in the hope of reducing their reoccurrence.

\section{Materials and Methods}

\section{Study design}

Our study was a cross-sectional descriptive study conducted in king Abdulaziz University Hospital, Jeddah, Saudi Arabia, over the period of 6 months - November 2011 to April 2012.

The study team developed a questionnaire that was designed to measure knowledge and evaluate the attitude and practice of physicians on reporting medical errors. The questionnaire constituted of 4 sections evaluating demographics of the interviewees, the knowledge on reporting errors, the physicians' attitude towards reporting, and the practice of reporting and concealing their errors. The questionnaires were then subjected to further evaluation in a pilot study to enhance its face validity. Our pilot study was conducted on 12 residents, and thus final modifications and amendments were performed prior to commencing the actual study.

A total of 250 questionnaires were printed and distributed to all physicians (Consultants, Specialists, and Residents) attending King Abdulaziz University Hospital. The study team received only 169 filled questionnaire forms back out of the 250 for analysis. The calculated return rate was found to be $67.6 \%$.

In order to ensure the quality of the data that were to be retrieved from the questionnaires, we sub-divided our study team into 3 divisions. Division 1 was assigned to review the answered questionnaires to confirm that all questions were answered. Division 2 was assigned to review the date before entering it into the software program for analysis. Division 3 was assigned to review a random sample of the questionnaires to detect pitfalls.

\section{Statistical analysis}

Statistical package of social science (SPSS) version 18 was used for statistical analysis. The qualitative data were presented in the form of number and percentage. Chi-square test was used as a test of significance for qualitative data; Yates correction was used when the expected cell was less than 5 . The quantitative data were expressed as means with standard deviations.

\section{Results}

We had a total of 169 participants in the study; of which $43.2 \%(n=73)$ were consultants, $34.3 \%(n=58)$ were residents and $22.5 \%(n=38)$ were specialists (22.5\%). Our study population had a mean (SD) age of 39.24 (11) years, and ranged between 25 and 65 years. $67.5 \%$ of the 


\begin{tabular}{|c|c|c|c|c|c|c|c|c|c|}
\hline Variable & \multicolumn{2}{|c|}{$\begin{array}{l}\text { Specialist } \\
\qquad \mathbf{n = 3 8} \\
(22.5 \%)\end{array}$} & \multicolumn{2}{|c|}{$\begin{array}{l}\text { Consultant } \\
\qquad \begin{array}{c}n=73 \\
(43.2 \%)\end{array}\end{array}$} & \multicolumn{2}{|c|}{$\begin{array}{c}\text { Resident } \\
\quad \mathbf{n}=58 \\
(34.3 \%)\end{array}$} & \multirow[t]{3}{*}{ P- Value } & \multicolumn{2}{|c|}{$\begin{array}{l}\text { Total } \\
n=169\end{array}$} \\
\hline \multirow[t]{2}{*}{ Age } & \multicolumn{2}{|c|}{$43.5(8.09)$} & \multicolumn{2}{|c|}{$46.2(8.77)$} & \multicolumn{2}{|c|}{$27.6(2.57)$} & & \multicolumn{2}{|c|}{$39.24(11)$} \\
\hline & $\mathbf{n}$ & $\%$ & $\mathbf{n}$ & $\%$ & $\mathbf{n}$ & $\%$ & & $\mathbf{n}$ & $\%$ \\
\hline $\begin{array}{l}\text { Gender } \\
\text { Male }\end{array}$ & 28 & 73.7 & 47 & 64.4 & 39 & 67.2 & 0.611 & 114 & 67.5 \\
\hline Female & 10 & 26.3 & 26 & 33.6 & 19 & 32.8 & & 55 & 32.5 \\
\hline $\begin{array}{l}\text { Nationality } \\
\text { Saudi }\end{array}$ & 13 & 34.2 & 60 & 82.2 & 55 & $94.8^{*}$ & 0.001 & 128 & 75.7 \\
\hline Other & 25 & $65.8^{*}$ & 13 & 17.8 & 3 & 5.2 & & 41 & 24.3 \\
\hline $\begin{array}{l}\text { Primary Work area } \\
\text { Anesthesiology }\end{array}$ & 2 & 5.3 & 6 & $8.2^{*}$ & 2 & 3.4 & & 10 & 5.9 \\
\hline Emergency medicine & 14 & $36.8^{*}$ & 2 & 2.7 & 5 & 8.6 & & 21 & 12.4 \\
\hline Clinical Laboratory & 4 & $10.5^{*}$ & 0 & 0 & 1 & 1.7 & & 5 & 3 \\
\hline Medicine & 3 & 7.9 & 14 & $19.2^{*}$ & 7 & 12.1 & 0.001 & 24 & 14.2 \\
\hline Obstetrics \& Gynecology & 2 & 5.3 & 14 & $19.2^{*}$ & 9 & 15.5 & & 25 & 14.8 \\
\hline Pediatrics & 2 & 5.3 & 9 & 12.3 & 9 & $15.8^{*}$ & & 20 & 11.8 \\
\hline Surgery & 9 & 23.7 & 20 & 27.4 & 21 & $36.2^{*}$ & & 50 & 29.6 \\
\hline Radiology & 2 & 5.3 & 8 & $11^{*}$ & 4 & 6.9 & & 14 & 8.3 \\
\hline Duration of work at KAUH & 8.55 & 5.98 & 16.89 & 7.03 & 2.68 & 1.97 & & 169 & \\
\hline $\begin{array}{l}\text { Country of UGE } \\
\text { Saudi Arabia }\end{array}$ & 13 & 34.2 & 56 & 76.7 & 52 & $89.7^{*}$ & 0.001 & 121 & 71.6 \\
\hline Other & 25 & $65.8^{*}$ & 17 & 23.3 & 6 & 10.3 & & 48 & 28.4 \\
\hline $\begin{array}{l}\text { Country of PGE } \\
\text { Saudi Arabia }\end{array}$ & 10 & 26.3 & 11 & 15.1 & 54 & $93.1^{*}$ & & 75 & 44.4 \\
\hline Middle East & 25 & $65.8^{*}$ & 2 & 2.7 & 3 & 5.2 & 0.001 & 30 & 17.8 \\
\hline Other & 3 & 7.9 & 60 & $82.2^{*}$ & 1 & 1.7 & & 64 & 37.9 \\
\hline
\end{tabular}

Table 1: Demographic Characteristics of Participants

*Statistically significant, KAUH=King abdulaziz university hospital PGE= Post graduate education UGE= Undergraduate education. 
participants were males, and $32.5 \%$ were females. More than $80 \%$ of the consultants and Results obtained from the section studying the practice of physicians in the questionnaire (Table 2) show that $87 \%(n=147)$ of our study sample claim that they have seen ME throughout their careers, and appears to be highest among consultants $94.5 \%(n=69)$. Only $56 \%(n=95)$ of our study sample claimed that they had reported the errors they had seen. Reporting of errors was also significantly higher among consultants $79.7 \%(n=55)$ compared to specialists and residents $(P=0.001)$. Furthermore, $48 \%(n=81)$ of the participants confessed that they had made ME themselves which was statistically insignificant, and only $35 \%(n=59)$ had reported their own mistakes to authorities in charge. Although insignificantly, consultants had the highest rate of selfreporting $81.1 \%(n=30)$. Unfortunately, only $17.2 \%(n=29)$ had their own ME investigated, and a significantly higher rate seen was amongst consultants 26\% ( $n=19) \quad(P=0.015)$. $24.9 \%(n=42)$ of the participants reported that they had been investigated for their colleagues $\mathrm{ME}$; this was of a higher rate in specialists $31.6 \%(n=12)$.

\begin{tabular}{lccccccccc}
\hline & \multicolumn{2}{c}{$\begin{array}{c}\text { Specialist } \\
\mathbf{n}=\mathbf{3 8}\end{array}$} & $\begin{array}{c}\text { Consultant } \\
\mathbf{n}=\mathbf{7 3}\end{array}$ & $\begin{array}{c}\text { Resident } \\
\mathbf{n}=\mathbf{5 8}\end{array}$ & $\begin{array}{c}\text { P- } \\
\text { Value }\end{array}$ & $\begin{array}{c}\text { Total } \\
\mathbf{n}=\mathbf{1 6 9}\end{array}$ \\
\hline & $\mathbf{n}$ & $\mathbf{\%}$ & $\mathbf{n}$ & $\mathbf{\%}$ & $\mathbf{n}$ & $\mathbf{\%}$ & & $\mathbf{n}$ & $\mathbf{\%}$ \\
\hline Have you ever seen ME? & 30 & 78.9 & 69 & $94.5^{*}$ & 48 & 82.8 & $0.034^{*}$ & 147 & $\mathbf{8 7}$ \\
\hline Did you report it? & 22 & 73.3 & 55 & $79.7^{*}$ & 18 & 37.5 & $0.001^{*}$ & 95 & 56 \\
\hline Have you ever made ME? & 18 & 47.4 & 37 & 50.7 & 26 & 44.8 & 0.798 & 81 & 48 \\
\hline Did you report it? & 14 & 77.8 & 30 & 81.1 & 15 & 57.7 & 0.105 & 59 & 35 \\
\hline $\begin{array}{l}\text { Have you ever been investigated for } \\
\text { your own ME? }\end{array}$ & 6 & 15.8 & 19 & $26^{*}$ & 4 & 6.9 & $0.015^{*}$ & 29 & 17.2 \\
\hline $\begin{array}{l}\text { Have you ever been investigated for } \\
\text { your colleague's ME? }\end{array}$ & 12 & 31.6 & 18 & 24.7 & 12 & 20.7 & 0.482 & 42 & 24.9 \\
\hline
\end{tabular}

Table 2: Practice of the Participant Group in Regard to Reporting Accidents

*Statistically significant

The level of physicians' knowledge on the subject of ME and their attitude towards reporting errors was assessed using 2 categories/formats of questions - level of agreement and level of disagreement.

The majority of participants $81 \% \quad(n=137)$ believe/consider that reporting ME is an ethical issue with the highest level of agreement found in the consultants group $100 \%(n=59)$. Also, $60.4 \%(n=102)$ agreed that reporting ME helps alleviate the feelings of guilt associated with committing the error and its subsequent effects. This was significantly highest among the consultants' group $78 \%(n=46)$.

Regarding the effect of RME, 36.1\% ( $n=61)$ thought it would decrease the rate of ME while a higher rate was observed in specialists $56.2 \%$ ( $n=18) .82 .8 \% \quad(n=140)$ thought RME would prevent future complications with higher rate in specialist $100 \%(n=32)$.

As regards to confidentiality of reported $M E$, 63.9\% ( $n=108$ ) thought that ME should be kept confidential. Specialists were the most $81.2 \%$ $(n=26)$ who felt that errors are best to be kept concealed. Furthermore, specialists [93.8\% $(n=30)]$ were the most who believed that ME should be discussed and solved within their respective departments and not disclosed to hospital administration (Table 3). As can be 
seen in Table 4, only $7.1 \%(n=12)$ of the participant thought it was not their responsibility to $\mathrm{RME}$ with highest rate in specialists $66.7 \%(n=4)$, and $6.5 \%(n=11)$ of them thought it might ruin their relationship with their colleagues with highest rate in specialists $66.7 \%(n=4) .2 .4 \%(n=4)$ reported that they might $\mathrm{RME}$ with highest rate in residents $40 \% \quad(n=2)$, and $5.9 \%$ thought confidentiality is not an issue with highest rate in consultants $42.9 \%(n=6)$.

\begin{tabular}{lccccccccc}
\hline Variable & \multicolumn{2}{c}{$\begin{array}{c}\text { Specialist } \\
\mathrm{n}=32\end{array}$} & \multicolumn{2}{c}{$\begin{array}{c}\text { Consultant } \\
\mathrm{n}=59\end{array}$} & \multicolumn{2}{c}{$\begin{array}{c}\text { Resident } \\
\mathrm{n}=53\end{array}$} & $\begin{array}{c}\text { P- } \\
\text { Value }\end{array}$ & \multicolumn{2}{c}{ Total } \\
\hline & $\mathrm{n}$ & $\%$ & $\mathrm{n}$ & $\%$ & $\mathrm{n}$ & $\%$ & & $\mathrm{n}$ & $\%$ \\
\hline Reporting is an ethical issue. & 30 & 93.8 & 59 & 100 & 48 & 90.6 & .182 & 137 & 81
\end{tabular}

Reasons behind concealment of errors were also studied; results are shown in Table 5 . Among our study group, $74 \%$ thought that participants $(94.7 \%)$ believed that it was imperative for our hospital to develop a suitable system to reduce the thought that

\section{Reporting helps alleviate feelings of} guilt.

$18 \quad 56.2 \quad 46 \quad 78.0 * \quad 38 \quad 71.7 \quad .005^{*} \quad 102 \quad 60.4$

\begin{tabular}{|c|c|c|c|c|c|c|c|c|c|}
\hline $\begin{array}{l}\text { Punishment will be less if ME is } \\
\text { reported. }\end{array}$ & 18 & $56.2^{*}$ & 28 & 47.5 & 15 & 28.3 & $.001^{*}$ & 61 & 36.1 \\
\hline Reporting prevents future complications. & 32 & 100. & 59 & 100. & 49 & 92.5 & .133 & 140 & 82.8 \\
\hline ME should be kept confidential. & 26 & $81.2^{*}$ & 45 & 76.3 & 37 & 69.8 & $.026 *$ & 108 & 63.9 \\
\hline $\begin{array}{l}\text { The problem should be solved within the } \\
\text { department. }\end{array}$ & 30 & 93.8 & 55 & 93.2 & 44 & 83.0 & .177 & 129 & 76.3 \\
\hline
\end{tabular}

Table 3: Percentage of agreement toward some issue relater to reporting ME among the study groups

*Statistically significant

occurrence of ME. In the questionnaires we had 6 suggested solutions. A significant number of the participants $69.2 \%$ protection of a physician's reputation is one of the main reasons behind under-reporting of $\mathrm{ME}$. Specialists $78.9 \%(n=30)$ were the most to give that response. Escaping penalty (avoiding punishment) $69.2 \% \quad(n=117)$ was the second most chosen answer by the participants as a reason behind concealment of $\mathrm{ME}$. On the other hand, $47.9 \% \quad(n=81)$ thought that physicians have no incentives to disclose errors and $40.2 \% \quad(n=68)$ thought that one would not report their own ME simply because the error would not be discovered. A total of 160 employing more nurses to the hospital would help to reduce the occurrence of $\mathrm{ME}$, this was mostly agreed upon by consultants. Also, $94.1 \%$ $(n=159)$ think that the training programs for employees need enhancement; specialists were the most who approved. Moreover, 79.9\% ( $n=135$ ), mainly consultants, believed that the use of experienced and well-trained physicians specifically in the ICU would reduce the incidence of errors. Additionally, $82.8 \%$ $(n=140)$, with the majority being residents, agreed upon reducing working hours to reduce medical errors. The suggestion of adding pharmacists to the hospital's team rounds was appreciated by $86.4 \% \quad(n=146)$ of the 
participants, mainly consultants. Only $34.9 \%$ license is a reasonable solution for preventing $(n=59)$ thought that suspending a physician's ME (Table 6).

\begin{tabular}{|c|c|c|c|c|c|c|c|c|c|}
\hline \multirow[t]{2}{*}{ Variable } & \multicolumn{2}{|c|}{$\begin{array}{c}\text { Specialist } \\
\mathrm{n}=6\end{array}$} & \multicolumn{2}{|c|}{$\begin{array}{c}\text { Consultant } \\
\mathrm{n}=14\end{array}$} & \multicolumn{2}{|c|}{$\begin{array}{l}\text { Resident } \\
\mathrm{n}=5\end{array}$} & \multirow[t]{2}{*}{$\begin{array}{c}\text { P- } \\
\text { Value }\end{array}$} & \multicolumn{2}{|c|}{ Total } \\
\hline & $\mathbf{n}$ & $\%$ & $\mathbf{n}$ & $\%$ & $\mathbf{n}$ & $\%$ & & $\mathbf{n}$ & $\%$ \\
\hline It is not my responsibility. & 4 & $66.7^{*}$ & 8 & 57 & 0 & .0 & $.023 *$ & 12 & 7.1 \\
\hline $\begin{array}{l}\text { I do not want to lose my good } \\
\text { relationship with my colleague. }\end{array}$ & 4 & 66.7 & 4 & 28.6 & 3 & 60 & .202 & 11 & 6.5 \\
\hline $\begin{array}{l}\text { I might be reported by my colleague in } \\
\text { turn. }\end{array}$ & 2 & 33.3 & 0 & .0 & 2 & 40 & .152 & 4 & 2.4 \\
\hline Confidentiality is an issue & 2 & 33.3 & 6 & 42.9 & 2 & 40 & .111 & 10 & 5.9 \\
\hline
\end{tabular}

Table 4: Percentage of disagreement toward some issue relater to reporting ME among the study

*Statistically significant

\begin{tabular}{lccccccccc}
\hline Variable & \multicolumn{2}{c}{$\begin{array}{c}\text { Specialist } \\
\mathbf{n = 3 8}\end{array}$} & $\begin{array}{c}\text { Consultant } \\
\mathbf{n}=\mathbf{7 3}\end{array}$ & $\begin{array}{c}\text { Resident } \\
\mathbf{n}=\mathbf{5 8}\end{array}$ & $\begin{array}{c}\text { P- } \\
\text { Value }\end{array}$ & Total \\
\hline $\begin{array}{l}\text { No incentives to error } \\
\text { disclosure. }\end{array}$ & 22 & 57.9 & 32 & 43.8 & 27 & 46.6 & .443 & 81 & 47.9 \\
\hline Avoiding punishment. & 30 & 78.9 & 43 & 58.9 & 44 & 75.9 & .078 & 117 & 69.2 \\
\hline $\begin{array}{l}\text { Avoiding damage to } \\
\text { reputation. }\end{array}$ & 30 & 78.9 & 53 & 72.6 & 42 & 72.4 & .181 & 125 & 74 \\
\hline It will not be discovered. & 18 & 47.4 & 25 & 34.2 & 25 & 43.1 & .436 & 68 & 40.2 \\
\hline
\end{tabular}

Table 5: The percentage of agreement toward causes of concealing errors

*Statistically significant

\section{Discussion}

ME are varied. The result is eventually the harm to patients. ME include errors in diagnosis, administration of drugs and surgical procedures amongst others. ME should be differentiated from malpractice in that the former is regarded as honest mistakes or accidents.

Generally, administration of inappropriate method of patient care that is opposed to standardized method of care, or failure of performing appropriate method by health care provider leads to ME. ME are usually described as human errors in healthcare e.g. $(7,8)$. inaccurate or incomplete diagnosis or management of a disease. A recent report "To Err Is Human" released by the Institute of Medicine (IOM) drew attention on the burden of medical errors. They concluded that among the American population, there are more deaths related to $\mathrm{ME}$ in hospitals than there are deaths related to injuries in vehicle accidents. Since the release of that report, numerous new efforts have been initiated to help reduce the incidence of ME (9). Furthermore, a recent study conducted on 184 residents found that being involved in a medical error was associated with a significant decrease in quality of life and increased rates of depression $(10,11,12)$. 


\begin{tabular}{|c|c|c|c|c|c|c|c|c|c|}
\hline \multirow[t]{2}{*}{ Variable } & \multicolumn{2}{|c|}{ Specialist $n=38$} & \multicolumn{2}{|c|}{ Consultant $n=73$} & \multicolumn{2}{|c|}{$\begin{array}{c}\text { Resident } \\
n=58\end{array}$} & \multirow[t]{2}{*}{ P- Value } & \multicolumn{2}{|c|}{ Total } \\
\hline & $\mathbf{n}$ & $\%$ & $\mathbf{n}$ & $\%$ & $\mathbf{n}$ & $\%$ & & $\mathbf{n}$ & $\%$ \\
\hline $\begin{array}{l}\text { Develop } \\
\text { systems for } \\
\text { preventing } \\
\text { ME. }\end{array}$ & 38 & 100.0 & 69 & 94.5 & 53 & 91.4 & .196 & 160 & 94.7 \\
\hline $\begin{array}{l}\text { Increase the } \\
\text { number of } \\
\text { nurses. }\end{array}$ & 26 & 68.4 & 57 & $78.1^{*}$ & 34 & 58.6 & $.005^{*}$ & 117 & 69.2 \\
\hline $\begin{array}{l}\text { Provide better } \\
\text { training for } \\
\text { workers. }\end{array}$ & 36 & 94.7 & 69 & 94.5 & 54 & 93.1 & .241 & 159 & 94.1 \\
\hline $\begin{array}{l}\text { Use only well- } \\
\text { trained } \\
\text { physicians in } \\
\text { the ICUs. }\end{array}$ & 26 & 68.4 & 64 & $87.7^{*}$ & 45 & 77.6 & $.006 *$ & 135 & 79.9 \\
\hline $\begin{array}{l}\text { Reduce } \\
\text { working hours } \\
\text { of physicians. }\end{array}$ & 30 & 78.9 & 59 & 80.8 & 51 & 87.9 & .513 & 140 & 82.8 \\
\hline $\begin{array}{l}\text { Include a } \\
\text { pharmacist on } \\
\text { hospital } \\
\text { rounds. }\end{array}$ & 30 & 78.9 & 68 & $93.2^{*}$ & 48 & 82.8 & $.011^{*}$ & 146 & 86.4 \\
\hline $\begin{array}{l}\text { Suspend the } \\
\text { licenses for } \\
\text { Physicians } \\
\text { who make } \\
\text { MEs. }\end{array}$ & 14 & 36.8 & 26 & 35.6 & 19 & 32.8 & .288 & 59 & 34.9 \\
\hline
\end{tabular}

Table 6: Percentage of agreement toward actions that should be taken to prevent ME *Statistically significant

Lawsuits related to ME are noticed to be increasing lately. It was reported that they are higher in obstetric practice $(27 \%)$, followed by general surgery (17\%) and other subspecialties $(13,14)$. Alsafi et al. evaluated the aspects behind physicians' attitudes toward medical error disclosure. They concluded that physicians are likely to disclose errors made by a colleague only if the error resulted in severe harm to the patient, and as such, ME go underreported for a variety of reasons. Their study was conducted among a single hospital in the kingdom of Saudi Arabia (15); therefore we felt the need to conduct a similar study in the hope of finding a solution to the problem in our country, and to see if results were reproducible. In our study, $87 \%$ of our participants had witnessed a medical error but only $56 \%$ of them reported those errors. This proves that errors are common but underreported. The reasons behind this needed to be investigated. Although most physicians 
believe that reporting is their responsibility (92.9\%), they may still be refraining from doing it. Our results suggest that a physician's reputation (74\%) and the fear of punishment $(69.4 \%)$ may contribute to the problem. Our results were similar to those obtained in the above mentioned studies $(10,13)$. Furthermore, our results significantly suggest that physicians feel that the employment of more nurses, highly qualified intensivists and clinical pharmacists to our institute can help reduce the occurrence of errors.

Limitations: Following the completion of our study, we realized that other factors must be taken into consideration. We believe that further classification of residents to juniors and seniors was needed. Since junior staff are still in training, their errors may well be higher and the fear of punishment may also prevent them from reporting. We also feel that the studies should have been conducted among nursing staff to investigate their perspectives. Additionally, we feel that the translation of the questionnaire to the staff's mother-tongue language may have helped the participants better answer the questions.

Most research papers have failed to clarify the scope of the problem because of several limitations. There are no studies that have examined the subject of $\mathrm{ME}$ from the perspective of different levels of physicians; only residents were included in previous studies. Also, sample sizes were small or personal narratives of individual physicians experiences following errors (16). Alsafi et al. carried out a study in Saudi Arabia and found that physicians are likely to disclose errors made by a colleague only if patients are severely harmed, and as such, medical errors go under-reported. Assurance of confidentiality and protection from backlash would promote medical error disclosure. ${ }^{15}$

\section{Conclusion:}

There is an agreement amongst physicians that reporting ME is an ethical issue. This however is not reflected in their practice. ME are underreported due to fear of indented reputation and suffering a penalty. Reinforcement of RME and reducing ME can be achieved by implementing strict guidelines, training personnel efficiently and using the experience of professionals in their appropriate fields. Health care institutions should adopt programs that help encourage medical professionals in reporting ME avoiding in the process the creation of a blame culture. We also recommend conducting further studies on the rates of errors and their reporting pre- and post-implementation of the above mentioned solutions.

\section{Disclosure of benefit}

The authors have no conflict of interest and are not sponsored or funded by any drug company.

\section{Conflicts of interest}

The authors declare that they have no conflict of interest.

\section{References}

1.Warrel C, Doshi A, Mayhew J, Thacker E, Mc Colgan P, Yates T, Rohrer J, Ingle G. Quality Improvement project: detecting, instigating and assessing effective hand over techniques. J Neurol Neurosurg Psychiatry. 2013 Nov;84(11):e2.

2.Rampatiqe R, Gamage S, Peiris S, Lopez AD. Assessing the reliability of causes of deaths reported by the vital registration system in Sri Lanka: Medical records review in Colombo. HIMJ.2013;42(3):20-8. 
3.Cheung KC, Van der Veen W, Bouvy ML,Wensing M, Van den Bent PM, de Smet PA. Classification of medication incidents associated with information technology. J Am Med Info Assoc. 2013 Sep24. doi:10.1136/amiajnl. 2013001818.

4.Smith MD, Birch JD, Renshaw M, Ottewill M. Qualitative analysis of factors leading to clinical incidents. Int. J Health Care Qual Assor.2013, 26(6):536-48.

5.Aljarallah JS, Alrowaiss N. The pattern of medical errors and litigation against doctors in Saudi Arabia. J Family Community Med. 2013 May;20(2):98-105.

6.Rideout D. 'Just Culture' encourages error reporting, improves patient safety. OR Manager. 2013 Jul;29(7):13-5.

7.Peikari HR, Zakaria MS, Yasin NM, Shah MH, Elhissi A. Role of computerized physician order entery usability in the reduction of prescribing error. Health inform Res. 2013 Jun;19(2):93-101.

8. James JT. A new, evidence based estimate of patient harms associated with hospital care. J Patient Saf.2013 Sep;9(3):122-8.

9.Mc Lennan S, Engel S, Ruhe K, Leu A, Schwappach D, Elger B. Implementation status of error disclosure standards reported by Swiss hospitals. Swiss Med Wkly.2013 Jul7:143.

10.Thomas L, Galla C. Republished: Building a culture of safety through team training and engagement. Postgrad Med J.2013 Jul;89(1053):394-401.

11.de Boer M, Boeker EB, Ramrattan MA, Kiewiet JJ,Dijkgraat MG,Boermeester MA, Lie-A-Huen L. Adverse drug events in surgical patients: an observational multicenter study. Int J Clin Pharm.2013 Oct. 35(5):744-52.

12.Lipschultz A, Adverse patient events involving medical devices. Biomed Instrum Technol.2013 Mar-Apr;47(2):152-5.

13.David G, Gunnarsson CL, Waters HC, Horblyuk R, Kaplan HS. Economic measurement of medical errors using a hospital claims database. Value Health. 2013 May-Apr; 16(2):305-10.

14.Radley DC, Wasserman MR,Olsho LE, Shoemaker SJ, Spranca MD, Bradshaw B.

15.Alsafi E, Baharoon SA, Tamim H, Hamdan H, Al Jahdali et al. Physicians attitudes toward reporting medical errors: An observational study at a general hospital in Saudi Arabia . Journal Of Patient safety, 2011; 7(3):144-147.

16.Singer SJ, Vogus TJ. Reducing hospital errors: Interventions that build safety culture. Annu Rev Public Health. 2013 ;34:373-96. 